\title{
Descriptive sensory profiling of thandai using principal component analysis
}

\author{
Manpinder Kaur, Rekha Chawla and S Sivakumar
}

Received: 29 June 2020 / Accepted: 08 December 2020 / Published online: 07 June 2021

(c) Indian Dairy Association (India) 2021

\begin{abstract}
Thandai being nutrient crammed pabulum is relished as a traditional milk-based beverage in India. Being indigenous drink, international and national level research work and the literature pertaining to the same is not available. Thus, the present study was undertaken to investigate and characterize the sensory attributes of commercially available thandai using Quantitative Descriptive Analysis (QDA) and Principal Component Analysis (PCA). QDA revealed statistically significant $(\mathrm{p}<0.05)$ difference in sensory attributes of thandai amongst the market samples. PCA identified three significant principal components that accounted for 93.01 per cent of the variation in the sensory data. Correlation matrix revealed many linear relationships between independent terms of sensory attributes.
\end{abstract}

Keywords: Milk beverage; 100-point scale; Principal component analysis; Quantitative descriptive analysis.

\section{Introduction}

The ancient philosopher has espoused the basic senses of human- sight, hearing, smell, taste and touch as "the windows of the soul." Sensory properties of products are absolutely necessary for the development of the product and can generally be described using terms defined within the categories of appearance, flavor and texture. Thandai, a traditional milk-based

Department of Dairy Technology, College of Dairy Science and Technology (CoDST), Guru Angad Dev Veterinary and Animal Sciences University (GADVASU), Ludhiana, 141004, Punjab, India

Rekha Chawla $(\square)$

Department of Dairy Technology, College of Dairy Science and Technology (CoDST), Guru Angad Dev Veterinary and Animal Sciences University (GADVASU), Ludhiana, 141004, Punjab, India

E-mail: mails4rekha@gmail.com; Phome: +91-70203-83177 beverage is easily digestible, highly refreshing, thirst quenching, appetizing and nutritionally far superior to many synthetic and aerated drinks. Being prepared from a combination of fruits and nuts with food additives, a proper blend of these is of utmost importance to bestow a peculiar sensory characteristic to the milk. The characterization of product is an important criterion to evaluate the product precisely and specifically. As the sensory quality is driving force for consumer acceptance and consequently demand laden (Desai et al. 2013), present study was undertaken to investigate and characterize the quality of commercially available thandai in terms of sensory attributes. The need to develop appropriate sensory characteristics that are product sensitive and specific has emerged in the recent years as the dairy and food industry has grown from the concept of "eat what we produce" to "produce what you want to eat". The application of statistical tools specifically QDA and PCA to develop these terminologies has been successfully employed in the recent years to characterize the sensory attributes of many food products.

Quantitative descriptive analysis (QDA) has been known as a tool for measurement and optimization of the aesthetically and measurable parameters of various products (Stone and Sidel, 1998). Descriptive sensory analysis of any product requires a descriptive technique and lexicon to describe the sensory properties in detail (Chawla et al. 2014). The principle involved in the QDA is highly dependent on the ability of the panelists to give reproducible results to yield quantitative product description which further can be evaluated statistically (Murray et al. 2001). Piggott and Hunter (1999), and Basker (1988) described screening tests and measures to monitor the performance of panelists for selection in panel. The critical part for any QDA is the scale usage and training of the panelists. Drake and Civille (2003), and Meilgard et al. (2007) reviewed these specifics and suggested that a panel or group of individuals to be employed for descriptive sensory analysis to obtain consistent results.

Principal component analysis (PCA) is a multi-variable analysis statistical tool (Martinez et al. 1998), widely used and involves reducing the original dependent variables (attributes) into a lower number of orthogonal (uncorrelated) synthesized variables 
(factors) based on pattern of correlation among the original variables (Lawless and Heymann, 1998). The application of PCA to the data obtained by QDA can be successfully employed to profile specific product characteristics, comparing and contrasting similar products based on attributes crucial of importance for sensory recognition and thus holding its promising position by altering product characteristics. Many researchers have employed the applications of QDA and PCA for the characterization of many food dairy products viz., ultrapasteurized milk, cheddar cheese, chocolate and soy flavored milk (Chapman et al. 2001; Young et al. 2004; Thompson et al. 2004; Keast and Lau, 2006), fermented food products like yoghurt (Desai et al. 2013; Ghosh and Chattopadhyay, 2012), labneh (Kaaki et al. 2012), and Indian delicacies like Doda burfi (Chawla et al. 2014) and Cham-Cham (Puri et al. 2016). In light of the above, considering the degree of success of QDA and PCA to descriptively illustrate the sensory attributes of food products, present study was envisaged to characterize the quality of commercially available thandai in terms of sensory attributes with the help of QDA and PCA as a statistical tool.

\section{Materials and Methods}

\section{Market survey}

Five best renowned commercial samples of thandai concentrate, in liquid form, were procured from the domestic market. Choosing the market samples was based on the brand image and consequent their sales in the market. Therefore, the brands chosen for the study were procured and coded for further analysis. For uniform product quality, homogenized toned milk was used for reconstitution studies, collected, and standardized to desired fat and SNF content, from the Experimental Dairy plant, College of Dairy Science and Technology for the preparation of thandai from market samples.

\section{Preparation of Thandai from commercial samples (as directed by manufacturer on the label)}

All the samples were reconstituted as per the procedure mentioned on the label, adding ice-chilled milk and decoction in requisite amounts. Careful instructions were taken into account while reconstitution as mentioned by the manufacturer.

\section{Sensory evaluation}

The sensory evaluation of the product was carried out by a panel of nine trained faculty members $(n=9)$ from Dairy Technology Department, working at College of Dairy Science and Technology, Guru Angad Dev Veterinary and Animal Sciences University, Ludhiana, India. The attribute terms adjudicating and characterizing procedures were developed using flavor profile methodology (Keane, 1992). The work done on sensory lexicons by Adhikari et al. (2011), Puri et al. (2016), Chawla et al. (2014), Civille et al. (2010), and Drake et al. (2010) was thoroughly studied to choose wide range of descriptive attributes, highly regarded for thandai. A descriptive language was developed for various attributes of thandai with the identified lexicon (Table 1). A total of 17 descriptors were selected under 4 heads. These four heads included color and appearance, flavor, mouthfeel and overall acceptability. Attributes were quantified with an intensity scale of 100 and analyzed using the procedure adopted by Chawla et al. (2014). After the screening of identifiable attributes and suitable terminology, the panelists were briefed and trained to accurately judge the characteristics of the product accordingly. The training period was continued until all the panelists grasped adequate knowledge to differentiate the intensity rates of each characteristic. An approximate sample size of $25 \mathrm{ml}$ was presented to the panelists for its evaluation at its best, keeping in view of judging all the attributes in a precise manner. To achieve reproducible sensory results, random coded samples were served to the panelists with a maximum of two samples served at a time with a temperature of $5^{\circ} \mathrm{C}$ (in closed cups to ease shaking of contents), and lukewarm water as a white between the different samples. Sensory analysis was performed thrice to eradicate any source of unbiases in the results. All of these triplicate formulations were served on different days to avoid misapprehensions. The environment of test performance was kept pleasant to minimize human errors during sensory analysis.

\section{Statistical analysis}

The data were analyzed with statistical analysis system (SAS) version 9.3.8 (SAS Inc., Cary, NC, USA). One-way analysis of variance (ANOVA) was performed on the descriptive data obtained during the present investigation for difference in means. Duncan's multiple range test was employed to evaluate statistically significant differences in mean values. Further, the mean scores of all 17 descriptors from descriptive analysis of commercial samples of thandai was subjected to Principal component analysis (PCA) using XL stat 32-bit software to have in depth understanding of the components of prime importance, maximum positive loadings and their interaction with other attributes in thandai.

\section{Results and Discussion}

\section{Descriptive sensory analysis}

Descriptive language for various attributes of thandai with the identified lexicon in presented in (Table 1). Puri et al. (2016) showed that the sensorial attributes of Cham-Cham, Doda burfi and greek yogurt differed with each other except few attributes and thus the need to develop the product specific lexicons to optimally describe the sensory attributes. Similarly, the sensory attributes of thandai differs from these products as depicted in Table 1, except for cooked flavor, and thus justifies the need to develop lexicons specific to thandai. The lexicon for thandai employed in PCA was figured out by finding its most significant 
characteristic features by a panel of trained sensory panelists. The attributes were distributed carefully under the main heads such as colour, consistency, sweetness and flavour. Mean sensory scores of market samples of thandai for colour and appearance, flavor, mouthfeel and overall acceptability can be fetched from the figure indicating spikes on spider/ radar web (Fig. 1). These plots were used for the graphical representation of the data generated by QDA methodology by plotting average intensity values on corresponding scale and then joining the points to create a visual profile or "fingerprint" of product attributes (Stone and Sidel, 1998) as these plots are often used for the graphical depiction of the data generated by QDA methodology (Murray et al. 2001). PCA not only helps in identifying underlying attributes of acceptance but also provides a means to check adulteration in many cases (Baquiran et al., 2019). Fig. 1 represents graphic representation of the data for five commercial samples of thandai in the form of spider web with a branch or spoke from a central point for each attribute. As presented by peaks and loops, sweetness was maximum in case of sample A and lowest in sample E. Similarly, score for watery consistency was highest for sample $\mathrm{E}$ and lowest for sample B. Indistinguishable work has been performed earlier in ultrapasteurized milk (Chapman et al. 2001), commercial lebneh samples (strained yoghurt) (Kaaki et al. 2012), Cham-Cham (Puri et al. 2016) and (Singh et al. 2019), where authors represented the descriptive sensory scores of panelists in pictorial form by creating spider plots.

The maximum score for milkier appearance and light brown to pistachio green colour was obtained with sample $\mathrm{C}(62.85)$ and $\mathrm{E}$ (65.0), respectively. Though, the colour and appearance scores were non-significant $(p \geq 0.05)$, these attributes influence food appreciation and quality. The average scores for cocoa, cardamom, almond/saffron/pistachio, cooked, malty, sweet, and sandal and aroma from milk fat and combination of nuts ranged from 11.57-29.0, 42.85-64.85, 58.57-73.0, 4.14-20.71, 8.0-23.57, 62.14$80.42,9.42-24.57,26.14-37.28$ and 32.85-51.71, respectively. Statistically, non-significant difference $(\mathrm{p} \geq 0.05)$ was observed

Table 1 Sensory lexicon developed for thandai

\begin{tabular}{l} 
Attribute name \\
\hline Milkier Appearance \\
Colour (Light brown to Pistachio \\
Cocoa aroma \\
Cardamom aroma \\
Almond/Saffron/Pistachio (A/S/P) \\
aroma \\
Cooked aroma
\end{tabular}

Cooked aroma

Malty aroma

Milk fat

Sweet

Sandal

Combination of several nuts

Smooth mouth feel

Coarse mouth feel

Presence of grainy particulates

Watery consistency

Rich mouth feel

Overall Acceptability
Attribute Definition

Having the appearance of milk, whitish, cloudy fluid which can mask other colours and flavours if present in extreme

The intensity of colour from light brown to pistachio green

Aromatics that specifically arises from complex biochemical and chemical reactions during the postharvest processing of raw cocoa beans

Aromatics associated with cardamom

Aroma that arises either due to almonds, saffron, pistachio or a combination thereof

Varies in intensity from sweet, pleasant, with slight sulfurous or custard notes, to caramelized or cabbage-like, which may be objectionable. Generally, arises from over cooking/roasting of nuts and milk.

Malt-like aroma or taste is characteristic of uncooked or roasted grain (including roasted corn, barley or wheat), malt extract

Fat contributed by milk provides a characteristic aroma to the product

Sweetness is the most recognized functional property of sugar; intensity depends on amount of sugar added and perceived by taste receptors present on tongue throughout mouth

Aromatics associated with sandalwood from trees in genus Santalum

A light, brown, slightly musty and nutty aroma contributed by various nuts infused into the product

It is the absence of any particles, lumps and bumps in the product. Signifies rough mouth feel. The coarseness in the product is resultant of ingredients added and are particularly large in size

The extent to which the product is composed of distinguishable pieces or grains of nuts.

Overly flowing consistency, lacks adequate consistency

Sufficient amount of milk fat, creamy mouth feel

Adequate to satisfy a need, requirement, or standard 
Fig. 1 Descriptive sensory profile of market samples of thandai on 100-point scale

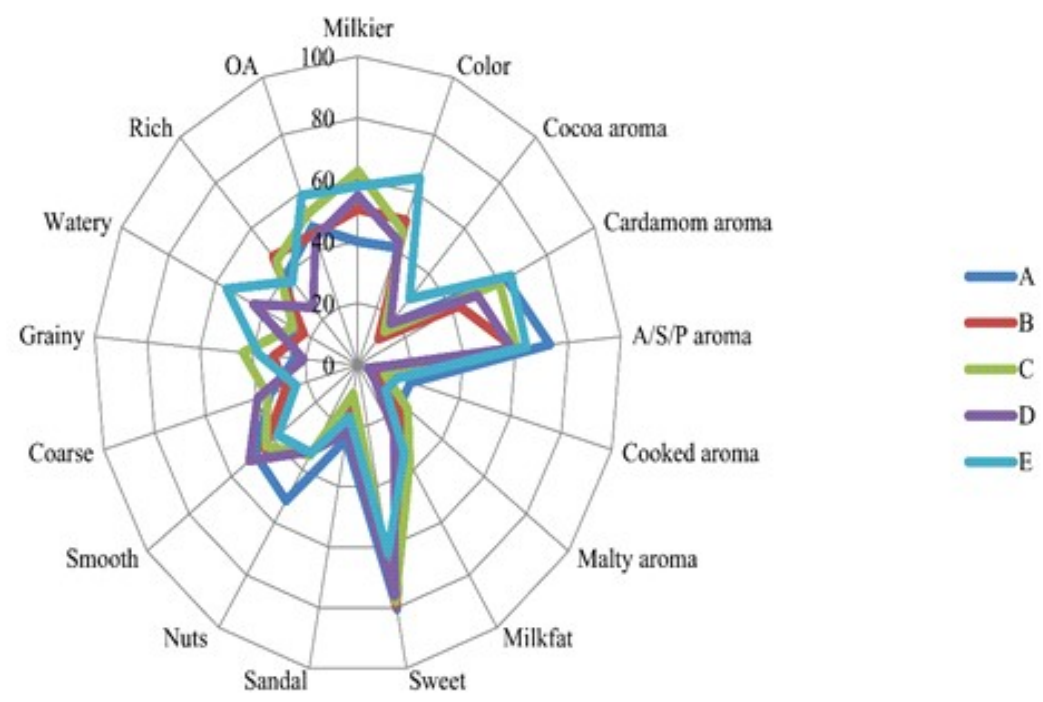

Table 2 Contribution of the variables in factor loadings for sensory analysis of thandai employing all attributes

\begin{tabular}{lllll}
\hline & F1 & F2 & F3 & F4 \\
\hline Milkier & 5.74 & 0.94 & 8.35 & 18.30 \\
Colour & 12.65 & 0.73 & 0.31 & 8.71 \\
Cocoa aroma & 5.63 & 12.55 & 0.16 & 0.16 \\
Cardamom aroma & 3.00 & 3.87 & 8.77 & 20.20 \\
A/S/P aroma & 0.33 & 2.18 & 20.60 & 0.27 \\
Cooked aroma & 0.58 & 2.18 & 19.96 & 1.11 \\
Malty aroma & 0.11 & 12.07 & 9.10 & 1.51 \\
Milk fat & 5.16 & 11.35 & 2.31 & 0.12 \\
Sweet & 10.01 & 6.02 & 0.63 & 0.65 \\
Sandal & 3.94 & 13.34 & 1.78 & 0.70 \\
Nuts & 2.99 & 0.63 & 18.24 & 0.02 \\
Smooth & 14.00 & 0.24 & 0.53 & 2.36 \\
Coarse & 8.56 & 0.00 & 0.76 & 33.19 \\
Grainy & 9.63 & 5.80 & 0.11 & 5.55 \\
Watery & 3.75 & 13.23 & 2.29 & 0.36 \\
Rich & 1.07 & 14.15 & 4.47 & 3.93 \\
OA & 12.86 & 0.72 & 1.64 & 2.86 \\
\hline
\end{tabular}

Values in bold correspond for each variable to the factor for which the squared cosine is the largest

in the sensory scores of the mentioned attributes except cooked and sweet aroma amongst the five commercial samples of thandai. The cooked aroma of sample B and D was observed close to nil with sensory scores of 5.0 and 4.14, respectively. The highest sensory scores for cooked aroma were observed for sample A and were significant $(\mathrm{p} \leq 0.05)$ w. r. t. sample B and D while non-significant w. r. t. sample $\mathrm{C}$ and $\mathrm{E}$. The sweetness scores of sample A was found definite with an average score of 80.42 whereas, in sample E sweetness was found close to moderate range with an average score of 62.14 and was significant $(\mathrm{p} \leq 0.05)$ with respect to each other.

Furthermore, the descriptors under mouth feel terminology, were smooth, coarse, grainy/ presence of particulates, watery and rich with their average scores as 37.85-51.42, 24.28-39.42, 20.71-43.71, $22.85-55.42,25.28-47.57$, respectively. The non-significant ( $\mathrm{p} \geq 0.05$ ) difference was observed for all the attributes excluding watery 
mouth feel. The watery mouth feel scores of sample B and E were significant $(p \leq 0.05)$ while non-significant $(p \geq 0.05)$ in relation to other commercial samples of thandai. The effectiveness of sensory procedure involved in this study can be computed using thorough evaluation of average sensory scores of milk fat aroma, watery mouthfeel and rich mouthfeel. Rich mouthfeel is closely linked with milk fat. Also, the taste, smell, mouth feel, and hedonic properties of fat all contribute to the popular concept of fat "taste" (Drewnowski, 1997). The overall acceptability scores ranged from 44.28-59.0 and were non-significant $(\mathrm{p} \geq 0.05)$. The maximum sensory scores for overall acceptability were observed with sample E (59.0) while sample D shows the minimum scores with an average of 44.28 .

\section{Principal Component Analysis}

PCA was performed on the 17 attributes measured from five commercial samples of thandai to simplify the interpretation of data obtained during QDA methodology. PCs were extracted on maximum variance values to acquire specific knowledge about primeval factors having critical importance among the sensorial descriptors (Puri et al. 2016). The PCA distinguished and segregated brands on the basis of sensory characteristics. The statistical parameters pertaining to the PCA for attributes pertaining to color and appearance, flavor, mouth feel and overall acceptability have been presented in Table 2 . The non-redundant terms indicated by PCA clearly differentiated thandai. In order to clarify groups of sensory characteristics of thandai, factor analysis was applied on the matrix of different sensory attributes. Similarly, distinct and highly reproducible patterns were also reported in soft drinks analysed by Zhang and Suslick (2007). On the basis of the eigen values, PCA distinguished and segregated different sensory attributes and the variables with eigen values over one was taken to explain the total variance. PCA differentiated samples with same characteristics in few quadrants while others with different characteristics remained segregated. Similar results were observed in case of fruit juices with different concentrations of acai (Sabbe et al. 2009) where juices with same characteristics combined in few quadrants while others with different characteristics remained segregated and other products like Doda burfi (Chawla et al. 2014), Cham-Cham (Puri et al. 2016) and fermented milk products (Ghosh and Chattopadhyay, 2012).

It was clear from the on the basis of eigen vector loadings, four PC's with an eigen value of $6.7,4.89,4.21$ and 1.19 were able to explain $39.41 \%, 28.81 \%, 24.79 \%$ and $6.99 \%$ of total variation, respectively. The cumulative variance explained by PC1 and PC2 was $68.22 \%$ while $100 \%$ of the total variance was explained by cumulating variance of all four PC's i.e. PC1, PC2, PC3 and PC4. The two PC's explaining $68.22 \%$ of total variation was bi-plotted to study the characteristics that are positively and negatively correlated and also to study the degree of correlation among the attributes. It is evident from the Fig.2 that in PC1, among all the attributes pertaining, sweetness and coarse mouth feel were

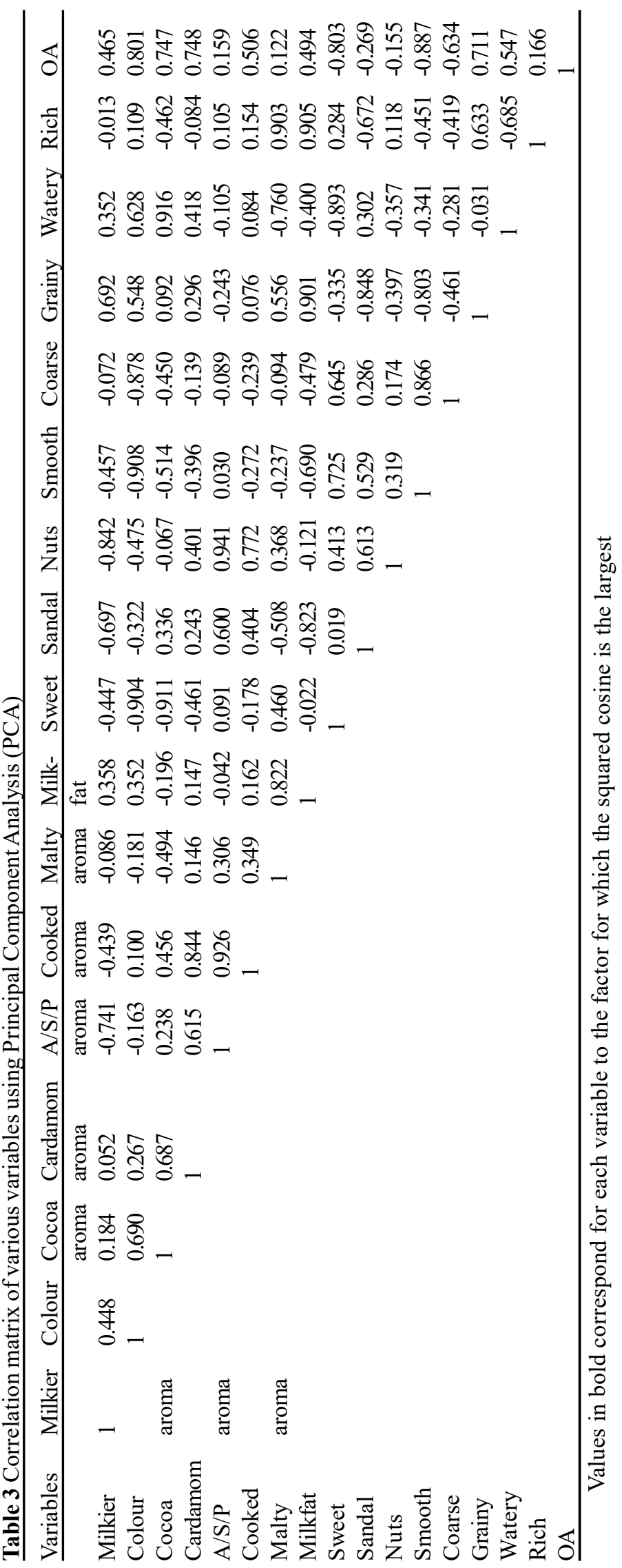


Fig.2 Biplots from $1^{\text {st }}$ and $2^{\text {nd }}$ principal components of PCA
Biplot (axes F1 and F2: $68.22 \%$ )

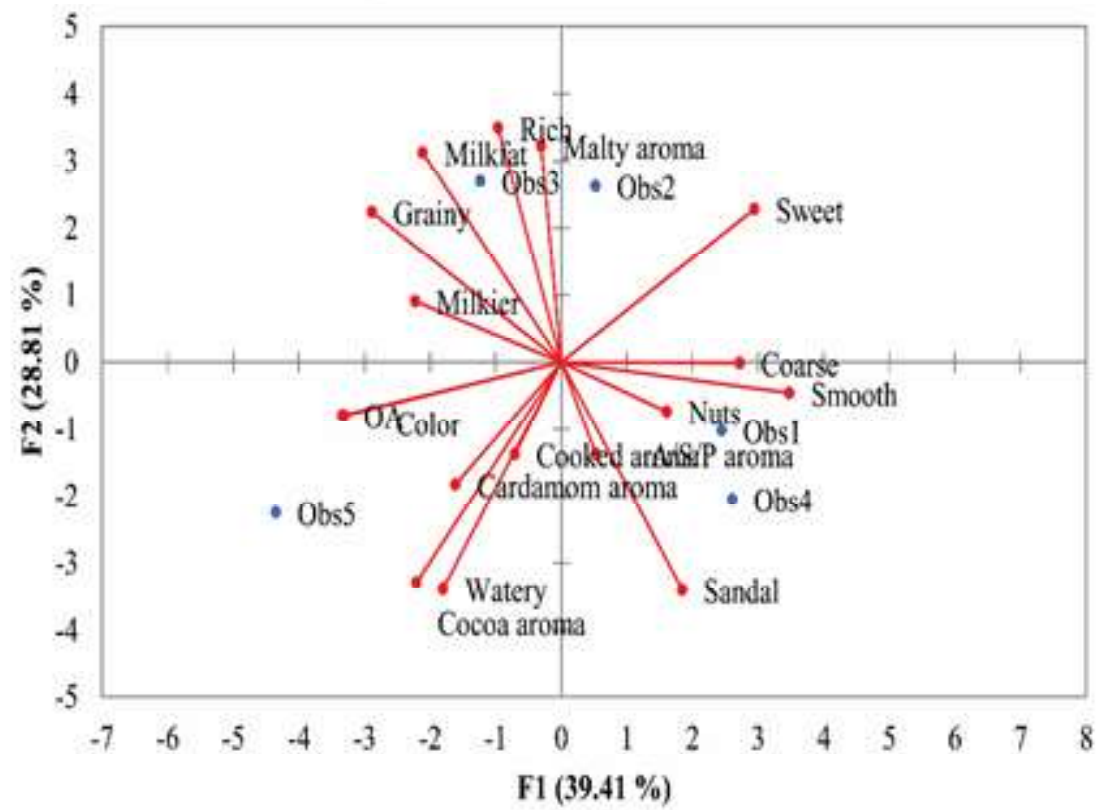

positively loaded, whereas sandal aroma, almond/saffron/ pistachio aroma, and smooth mouthfeel were in negative correlation. Similarly, in PC2 major sensory attributes like milk fat, milkier appearance, richness and granularity were positively loaded, whereas watery, cocoa, and cooked aroma was negatively correlated. The degree of difference or similarity between two attributes is proportional to the distance between the location of any two attributes (Chawla et al. 2014).

Factor analysis revealed, component 1 positively and significantly loaded with milkier (5.74), color (12.65), sweet (10.01), smooth (14.00), coarse (8.56), grainy (9.63) and overall acceptability (12.86). Similarly, cocoa aroma, malty aroma, milk fat, sandal, watery and rich were found positive in component 2 with values $12.55,12.07,11.35,13.34,13.23$ and 14.15 (Table 2). The characteristics of prime importance were found loaded in sample $\mathrm{C}$ whereas cocoa aroma, watery mouth feel was dominating characters in sample $\mathrm{E}$ and were less desired by consumers. Sweetness, the identifying and important attribute was found highest in sample B.

Correlation matrix (Table 3) revealed many expected correlations and was conducted to check if linear relationships existed between individual terms of sensory attributes. Milkier appearance was positively correlated with almond/saffron/ pistachio aroma as more of nuts and distinct flavors can mask milkier appearance. Grainy mouth feel was positively correlated with overall acceptability whereas smoothness was negatively correlated with overall acceptability, this provides evidence that panelists liked more granulated product. The same holds true as well, thandai being a traditional household preparation people relish coarse particles in this drink to chew in their mouth. The
Table 4 Enhanced contribution of variables in factor pattern loadings for sensory analysis of thandai omitting attributes of null importance

\begin{tabular}{lll}
\hline Sensory attribute & F1 & F2 \\
\hline Colour & 15.69 & 0.10 \\
Cocoa aroma & 8.63 & 18.57 \\
Cardamom aroma & 5.83 & 9.94 \\
A/S/P aroma & 0.011 & 8.15 \\
Milk fat & 6.15 & 18.27 \\
Sweet & 13.15 & 6.24 \\
Nuts & 2.17 & 4.43 \\
Smooth & 17.83 & 1.14 \\
Grainy & 11.46 & 10.77 \\
Rich & 1.21 & 21.42 \\
OA & 17.86 & 0.93 \\
\hline
\end{tabular}

color showed a positive degree of correlation with cocoa aroma and overall acceptability. A positive correlation was observed for cardamom aroma and cocoa aroma with overall acceptability as well as between milk fat and richness and also between milk fat and graininess (Table 3). These results suggest that high grainy and rich mouth feel, good color and cardamom aroma necessarily drive the consumer liking.

Considering presence of variables with non-significant contributions, few variables like malty, cooked, and sandal aroma, along with coarse, and watery mouthfeel were removed from data set and it did not result in a loss of explained variability by PCA, suggesting that these aroma and mouth feel terms could be safely removed from the sensory language without a loss of product differentiation (Table 4). The results obtained after factor analysis 
validated the same hence the attributes were omitted from the analysis and data was reanalyzed depicting PC1 and PC2 explaining 47.50 and $26.08 \%$ of the variation, respectively. The three PC's were able to explain 95.57 per cent of the total variation. However, the wide variability among different sensory attributes could be attributed to difference in manufacturing practices, varying ingredient quantity and quality and the processing techniques of the final product.

\section{Conclusions}

The demand to develop consumer specific products has caused the researchers to develop sensory lexicons pertaining to that particular product. Thandai being an indigenous drink carries none of the literature available either of the international or national level. Therefore, this necessitates the need to characterize the sensory attributes of commercially available thandai using quantitative descriptive analysis (QDA) and principal component analysis (PCA). The five commercial samples of thandai showed a wide variation with respect to sensory lexicons defined for thandai. Among the five samples surveyed, sample $\mathrm{C}$ showed maximum positive loadings and scoring for sensory attributes. Attributes such as milk fat, richness, grainy, and milkier were identified as key attributes by PCA. Hence, these attributes may be regarded as prime sensory quality indicators in thandai and may be used for the development of the product.

\section{References}

Adhikari K, Chamber E, Miller R, Vazquez LA, Bhumiratana N, Phillip C (2011) Development of a lexicon for beef flavor intact muscle. J Sens Stud 26:413-420

Basker D (1988) Applied Sensory Analysis Chapter II. pp. 125-143. CRC Press, Boca Raton, New York

Baquiran VD, Bate JAM, Sembrano MJB, Villaverde JF and Magwili GV (2019). Determination of Adulteration in Philippine Coconut Wine using Principal Component Analysis and Soft Independent Modelling of Class Analogy, IEEE International Conference on Consumer Electronics - Asia (ICCE-Asia), Bangkok, Thailand, 2019, pp. $25-$ 29, doi: 10.1109/ICCE-Asia46551.2019.8942226.

Chapman KW, Lawless HT, Boor KJ (2001) Quantitative descriptive analysis and principal component analysis for sensory characterization of ultrapasteurized milk. J Dairy Sci 84:12-20

Chawla R, Patil GR, Singh AK (2014) Sensory characterization of doda burfi (Indian milk cake) using Principal Component Analysis. J Food Sci Technol 51:558-564

Civille GV, Lapsley K, Huang G, Yada S, Seltsam J (2010) Development of an almond lexicon to assess the sensory properties of almond varieties. J Sens Stud 25:146-162

Ghosh D, Chattopadhyay P (2012) Application of principal component analysis (PCA) as a sensory assessment tool for fermented food products. J Food Sci Technol 49:328-334

Desai NT, Shepard L, Drake MA (2013) Sensory properties and drivers of liking for Greek yogurts. J Dairy Sci 96:7454-7466

Drake MA, Civille GV (2003) Flavor lexicons. Compr Rev Food Sci Food Saf $2: 33-40$
Drake M.A, JonesVS, Russell T, Harding R, Gerard PD (2007) Comparison of lexicons for descriptive analysis of whey and soy proteins in New Zealand and the U.S.A. J Sens Stud 22:433-452

Drake SL, Yates MD, Drake MA (2010) Development of a flavor lexicon for processed and imitation cheese. J Sens Stud 25:720-739

Drewnowski A (1997) Taste preferences and food intake. J Annu Rev Nutr 17:237-253

Hunter EA, Mcewan JA (1998) Evaluation of an international ring trial for sensory profiling of hard cheese. Food Qual Prefer 9:343-354

Kaaki D, Kebbe OB, Najm NE, Olabi A (2012) Preference mapping of commercial Labneh (strained yogurt) products in the Lebanese market. J Dairy Sci 95:521-532

Keane P (1992) The flavor Profile. In: ASTM Manual on Descriptive Analysis Testing (13th edition). pp. 5-14. Hootman, R.C. (Ed.) ASTM, Philadelphia, PA

Keast RSJ, Lau JJ (2006) Culture-specific variation in the flavor profile of Soymilks. J Food Sci 71:567-572

Lawless HT, Heymann H (1998) Sensory Evaluation of food: Practice and Principles, Chapter II. pp. 165-167. Chapman and Hall, New York

Martinez ME, Marshall JR, Sechrest L (1998) Invited Commentary: factor analysis and the search for objectivity. Am J Epidemiol 148:17-19

Maynard AA, Pangborn RM, Roessler EB (1965) Principles of Sensory Evaluation of Food, Chapter III. pp. 220. Academic Press, London

Meilgard MC, Civille GV, Carr BT (2007) Sensory Evaluation Techniques, Chapter I. pp. 8. CRC Press, New York

Murray JM, Delahunty CM, Baxter IA (2001) Descriptive sensory analysis: Past, present and future. Food Res Int 34:461-471

Parente ME, Gambaro A, Ares G (2008) Sensory characterization of emollients. J Sens Stud 23:149-161

Piggott JR, Hunter EA (1999) Evaluation of assessor performance in sensory analysis. Ital J Food Sci 4:289-303

Puri R, Khamrui K, Khetra Y, Malhotra R, Devraja HC (2015) Quantitative descriptive analysis and principal component analysis for sensory characterization of Indian milk product cham-cham. J Food Sci Technol 53:1238-1246

Sabbe S, Verbeke W, Deliza R, Matta VM, Van P (2009) Consumer liking of fruit juices with different acai (Euterpe oleracea Mart) concentrations. J Food Sci 74:171-176

Singh R, Prasad W, Khamrui K (2019). Sensory characterization of pinni - a milk cereal based sweet using quantitative descriptive analysis and principal component analysis. Indian J Dairy Sci 72(3):241248

Stone H, Sidel JL (1998) Quantitative descriptive analysis: developments, applications and the future. J Food Technol 52:48-52

Thompson JL, Drake MA, Lopetcharat K, Yates MA (2004) Preference mapping of commercial chocolate milks. J Food Sci 69:406-413

Thompson K, Chambers DH, Chambers E (2009) Sensory characteristics of ice cream produced in the United States and Italy. J Sens Stud 24:396-414

Youn K, Park JH, Lee J, Jeong WS, Tang CH, Jun M (2016) The identification of Biochanin A as a potent and selective ā-Site appcleaving enzyme 1 (Bace1) inhibitor. J Hum Nutr 8:637

Young ND, Drake M, Lopecharat K, Daniel MR (2004) Preference mapping of Cheddar cheese with varying maturity levels. J Dairy Sci 87:11-19

Zhang C, Suslick KS (2007) Colorimetric sensor array for soft drink analysis. J Agric Food Chem 55: 237-242 